\title{
Pumped Heat Electrical Storage (PHES) Status in India
}

\author{
Dilip Joshi \\ Retired Superintending Engineer \\ State Load Despatch Center, \\ Vadodara, India
}

\author{
Yashita Mehta \\ Intern \\ State Load Despatch Center, \\ Vadodara, India
}

\begin{abstract}
The growing economy with corresponding increase in power demand causes more challenges in power sector of developing countries. In India, the increase in peak power demand necessitates energy storage schemes over and above the storagehydro-, oil- and gas-based peak power plants to ensure power system stability. This paper evaluates the progress and potential of PHS as a key sector in India, ideally requiring at least US\$20 bn of new investment in the coming decade.
\end{abstract}

Keywords—Hydropower Plant; Pumped storage system

\section{I.INTRODUCTION}

Due to high RE Generation penetration, System operators are facing difficulty in grid operation. Due to uncertainty in Wind Generation, it is difficult to predict it and plan other Generators accordingly. The pattern of wind generation is not similar in a day or next day/all days. Sometimes it is high during day and low at night,or high during night and sometimes there is frequent sudden drops/rise in wind generation in a day. Energy storage technology may resolve this issue by storing RE Generation when there is low demand and release it when demand comes.

In utility energy storage schemes, the Pumped storage schemes attract more attention even in the developed countries due to its unique operational flexibility over other energy storage systems. In India, the availability of suitable topographies, hydro-thermal ratio imbalance in various regions, and optimal storage capacity for flexible power system operation gives a thought for the planners and executors to implement these schemes to meet peak demands.

This review presents a critical review of the necessity of pumped storage schemes in India and reveals that the major constraint for pumped storage operation in India is the deficit of off-peak power available in all the regional grids except north-east region for pumping at present. But the current adversity is likely to be gradually solved by the commissioning of newly proposed power projects. Fixing of a separate operational tariff for pumped storage schemes throughout the country is another requirement for which the government has set up a one-man committee to analyze the feasibility for this peak tariff. Nonavailability of lower tail pools and irrigation needs also causes poor pumping operations in some cases. However, most of the states in India are evincing interest in pumped storage schemes and proposals are being submitted to central government for securing stations clearance.

\section{TYPES OF HYDROPOWER PLANTS}

There are three types of hydropower facilities: impoundment, diversion, and pumped storage. Some hydropower plants use dams and some do not. The images below show both types of hydropower plants.

\section{A) IMPOUNDMENT}

The most common type of hydroelectric power plant is an impoundment facility. An impoundment facility, typically a large hydropower system, uses a dam to store river water in a reservoir. Water released from the reservoir flows through a turbine, spinning it, which in turn activates a generator to produce electricity. The water may be released either to meet changing electricity needs or to maintain a constant reservoir level.

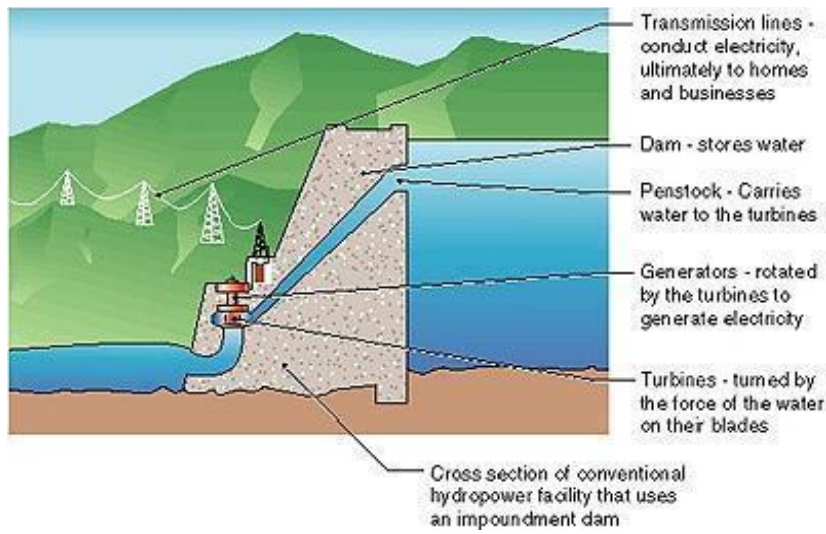

Figure I. Impoundment type

B) DIVERSION

A diversion, sometimes called run-of-river, facility channels a portion of a river through a canal or penstock. It may not require the use of a dam. 


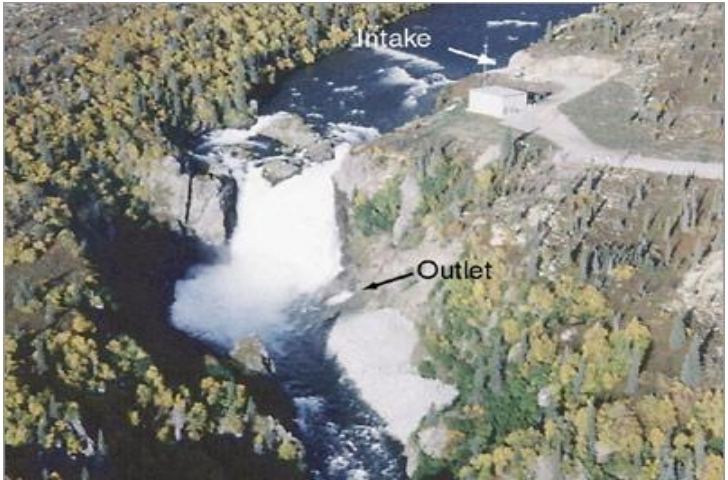

Figure II. Diversion type

\section{C) PUMPED STORAGE}

Another type of hydropower called pumped storage works like a battery, storing the electricity generated by other power sources like solar, wind, and nuclear for later use. It stores energy by pumping water uphill to a reservoir at higher elevation from a second reservoir at a lower elevation. When the demand for electricity is low, a pumped storage facility stores energy by pumping water from a lower reservoir to an upper reservoir. During periods of high electrical demand, the water is released back to the lower reservoir and turns a turbine, generating electricity.

\section{III.. PUMPED STORAGE SYSTEM}

In Pumped Heat Electrical Storage (PHES), electricity is used to drive a storage engine connected to two large thermal stores. To store electricity, the electrical energy drives a heat pump, which pumps heat from the "cold store" to the "hot store" (similar to the operation of a refrigerator). To recover the energy, the heat pump is reversed to become a heat engine. The engine takes heat from the hot store, delivers waste heat to the cold store, and produces mechanical work. When recovering electricity, the heat engine drives a generator.

\section{A. Types of Pumped storage plants}

Pumped-storage hydropower (PSH) is a type of hydroelectric energy storage. It is a configuration of two water reservoirs at different elevations that can generate power (discharge) as water moves down through a turbine; this draws power as it pumps water (recharge) to the upper reservoir.

PSH capabilities can be characterized as open loop-where there is an ongoing hydrologic connection to a natural body of water-or closed loop, where the reservoirs are not connected to an outside body of water.
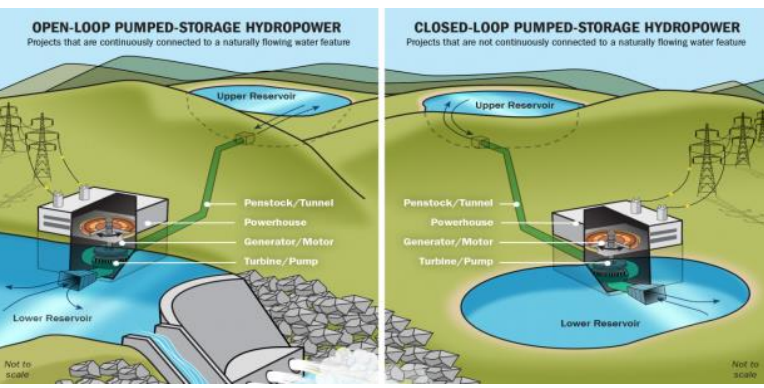

Figure III. Pump Storage Hydropower

- Pumped-storage hydroelectricity (PSH) is a type of hydroelectric power generation used by some power plants for load balancing. The method stores energy in the form of potential energy of water, pumped from a lower elevation reservoir to a higher elevation. Lowcost off-peak electric power is used to run the pumps. During periods of high electrical demand, the stored water is released through turbines to produce electric power. Although the losses of the pumping process makes the plant a net consumer of energy overall, the system increases revenue by selling more electricity during periods of peak demand, when electricity prices are highest.

Pumped storage is the largest-capacity form of grid energy storage available, and, as of March 2012, the Electric Power Research Institute (EPRI) reports that PSH accounts for more than $99 \%$ of bulk storage capacity worldwide, representing around 127,000 MW. PSH reported energy efficiency varies in practice between $70 \%$ and $80 \%$, with some claiming up to $87 \%$.

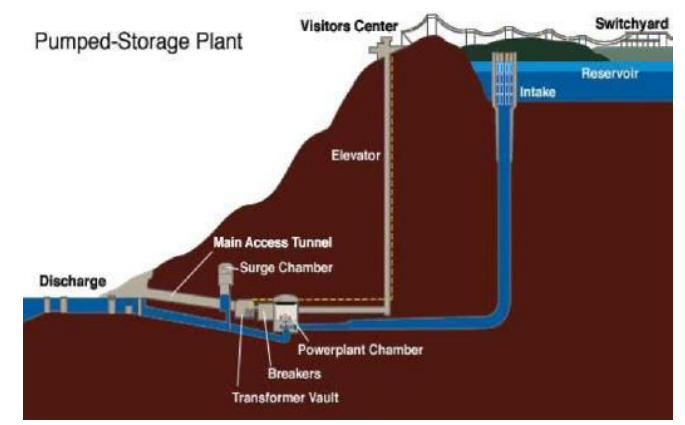

Figure IV. Cross Section of Pump storage plant

This system may be economical because it flattens out load variations on the power grid, permitting thermal power stations such as coal-fired plants and nuclear power plants and renewable energy power plants that provide base-load electricity to continue operating at peak efficiency (Base load power plants), while reducing the need for "peaking" power plants that use the same fuels as many base load thermal plants, gas and oil, but have been designed for flexibility rather than maximal thermal efficiency. However, capital costs for purpose-built hydro storage are relatively high.

Along with energy management, pumped storage systems help control electrical network frequency and provide reserve generation. Thermal plants are much less able to respond to sudden changes in electrical demand, potentially causing frequency and voltage instability. Pumped storage plants, like other hydroelectric plants, can respond to load changes within seconds.

A new use for pumped storage is to level the fluctuating output of intermittent energy sources. The pumped storage provides a load at times of high electricity output and low electricity demand, enabling additional system peak capacity. In certain jurisdictions, electricity prices may be close to zero or 
occasionally negative, on occasions that there is more electrical generation than load available to absorb it; although at present this is rarely due to wind alone, increased wind generation may increase the likelihood of such occurrences. It is particularly likely that pumped storage will become especially important as a balance for very large scale photovoltaic generation.

A new concept is to use wind turbines or solar power to drive water pumps directly, in effect an 'Energy Storing Wind or Solar Dam'. This could provide a more efficient process and usefully smooth out the variability of energy captured from the wind or sun

Small pumped-storage hydropower plants can contribute to distributed energy storage and decentralized peak and balancing electricity. Such plants can be built to integrate at the regional level intermittent renewable energy sources.

PSH accounts for more than $99 \%$ of bulk storage capacity worldwide: around $127,000 \mathrm{MW}$, according to the Electric Power Research Institute (EPRI), the research arm of America's power utilities.

Yet despite its dominance, traditional PSH has limited capacity for expansion. The kind of sites needed for such systems are few and far between. As a result, several firms are devising new forms of PSH.

PHES requires the following elements: two low cost (usually steel) tanks filled with mineral particulate (gravel-sized particles of crushed rock) and a means of efficiently compressing and expanding gas. A closed circuit filled with the working gas connects the two stores, the compressor and the expander. A monatomic gas such as argon is ideal as the working gas as it heat/cools much more than air for the same pressure increase/drop - this in turn significantly reduces the storage cost.

The process proceeds as follows: the argon, at ambient pressure and temperature (top left limb of the circuit on the diagram), enters the compressor (diagram shows a rotating compressor symbol - all equipment is in fact reciprocating). The compressor is driven by a motor/ generator (top) using the electricity that needs to be stored (yellow arrows at top). The argon is compressed to $12 \mathrm{bar},+500^{\circ} \mathrm{C}$. It enters the top of the hot storage vessel and flows slowly (typically less than $0.3 \mathrm{~m} / \mathrm{s}$ ) through the particulate, heating the particulate and cooling the gas. As the particulate heats up, a hot front moves down the tank (at approximately $1 \mathrm{~m} /$ hour). At the bottom of the tank, the argon exits, still at nearly 12 bar but now at ambient temperature. It then enters the expander (bottom) and is expanded back to ambient pressure, cooling to minus $-160^{\circ} \mathrm{C}$. The argon then enters the bottom of the cold vessel and flows slowly up, cooling the particulate and itself being warmed. It leaves the top of the tank back at ambient pressure and temperature.

To recover the power (i.e. discharge), the gas flow (and all arrows on the diagram) is simply reversed. Argon at ambient temperature and pressure enters the cold tank and flows slowly down through it, warming the particulate and itself becoming cold. It leaves the bottom of the tank at $-160^{\circ} \mathrm{C}$ and enters the compressor. It is compressed to 12 bar, heating back up to ambient temperature. It then enters the bottom of the hot tank. It flows up, cooling the particulate and itself being warmed to $+500^{\circ} \mathrm{C}$. The hot pressurized gas then enters the expander where it gives up its energy producing work, which drives the motor/generator. The expected $\mathrm{AC}$ to $\mathrm{AC}$ round trip efficiency is $75-80 \%$.

\section{- Gravity Power Storage System-}

Gravity Power Storage system is a mini version of Pump Hydro storage system -developed by USA based company using same principal of Pump storage.

A Gravity Power Model (GPM) is being developed to serve the Ancillary Services markets - namely frequency regulation. Regulation is a service purchased by grid operators to slow down or speed up the speed (technically the frequency) of the grid to ensure stability of power systems. Greater wind penetration on the grid increases the need for regulation services.

Ancillary GPM will be rated at approximately $25 \mathrm{MW}$ for about 20 minutes of storage. This market is a power market, not an energy storage market per se, thus the cost $/ \mathrm{kW}$ (and not the cost/kWh or efficiency) is the critical metric. A-GPMs will end up being about $\$ 1000 / \mathrm{kW}$ in the U.S. and cheaper elsewhere. This easily beats batteries and flywheels for cost and GPMs will last for decades unlike batteries and flywheels. The ramp rates are much faster than combustion gas turbines used for regulation, so A-GPMs should be a market leader for this service.

Ancillary GPMs will allow the Generator to achieve cash-flow positive and profitability within five years and allow full prove out of core technical subsystems at scale, such as seals, shaft linings, controls and more. A-GPMs are a path to significantly reducing risk and optimizing subsystems, while moving toward our massive market, the peaker plant GPMs, which are rated at much higher capacities and have significantly deeper shafts.

\section{The Gravity Power Module :}

- The Gravity Power Module, or GPM, is an innovative, in-ground modular pumped storage hydropower technology that offers the proven benefits of conventional pumped storage hydropower without the conventional challenges of siting, permitting and cost and time to market.

- Each GPM employs two deep, water-filled shafts, one of which stores energy in heavy pistons that move vertically within this shaft. The smaller shaft of the two is a return pipe which connects each piston shaft to a ground level, Francis pump turbine. The system is filled once with clean water and sealed. As a piston falls, it forces water through the pump-turbine to generate electricity. In storage mode, grid electricity drives the pump-turbine, forcing the weight up the shaft. Clusters of GPMs, with hundreds of MWh of storage per GPM, can replace gas turbine peaking 
plants at lower levelized costs of electricity. GPMs will also firm giga watts of variable renewable generation, a necessity for stable global grid systems. Figure shows the GPM concept.

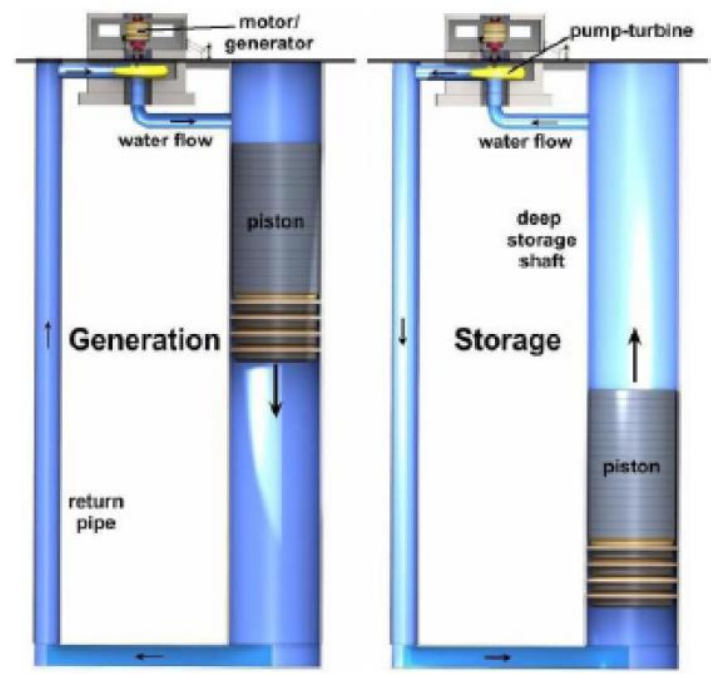

Figure V . Typical Gravity Power module

GPM system advantages include:

- modularity;

- use of existing technology;

- no new factories required,

- low land requirements and no emissions;

- flexible siting; fast permitting;

- rapid construction; local material and labour,

- low cost per megawatt-hour; low maintenance cost;

- $\quad$ long lifetime;

- $\quad$ high efficiency (up to $80 \%$ ); and

- a short time from project start to revenue.

- Performs better than thermal plants

- System payback time: 5-10 years

- System lifetime: $30+$ years

\section{PUMP STORAGE STATUS AT INDIA}

Five years ago, India committed to an ambitious transformational target of 175 gigawatts $(\mathrm{GW})$ of renewable energy installations by 2022. The target for new installs of 30$40 \mathrm{GW}$ annually puts India on track to be one of the largest developers of renewables globally, potentially second only to China.

To do this, India must continue to modernize its electricity system, developing a dynamic time of day pricing signal for producers and consumers alike. Additionally, US\$10-20 bn annually must continue to be invested in expanding the national grid transmission and distribution system. Flexible on-demand peaking capacity of all types also needs to be added to balance low cost but highly variable renewable energy generation.

Storage is another key issue and IEEFA expects pumped hydro storage (PHS) to play a central role. PHS works by storing energy in water in an upper reservoir, pumped from a second reservoir at a lower elevation when there is excess power in the system. When there is demand for energy, the water in the upper reservoir is released and as it falls, it turns turbines that create the power.

Plans have been formulated for India to become a world leader in PHS. Some 2.6 GW of PHS are already operational with another $3.1 \mathrm{GW}$ under construction, albeit much delayed. Proposals for another $8.9 \mathrm{GW}$ are on the drawing board. However, given the enormous social costs and absence of a strong price and policy signal for producers and consumers, progress has been stalled for many years.

There are a number of reasons for the delay in PHS projects. Large hydro power projects in India commonly get embroiled in social and political issues mostly related to loss of significant areas of agricultural flood plains and forest lands, and forced relocation without just compensation for affected rural communities. Interstate disputes over water rights compound environmental issues such as flood safety concerns and agricultural needs.

Further, with seasonal water flows and mountainous, remote locations, hydro-electricity requires very patient capital, and engineering technology is certainly challenged. India's enormous plans for new low-cost, deflationary, domestic renewable energy also comes with an associated, critical need to accelerate the deployment of storage.

At present, 11 pumped storage schemes with an installed capacity of $4804 \mathrm{MW}$ are functioning in the country and another 1000 MW capacity plant is under construction. ... During offpeak hours of the grid, the water is pumped from the lower to the upper reservoir where it is stored.

\begin{tabular}{|c|c|c|c|}
\hline Name of the Project & State & \begin{tabular}{|c|} 
Installed \\
Capacity \\
(MW)
\end{tabular} & $\begin{array}{l}\text { Pumping Mode } \\
\text { operation }\end{array}$ \\
\hline Kadamparai & Tamil Nadu & 400 & Operational \\
\hline Bhira & Maharashtra & 150 & Operational \\
\hline Sisailam & Andhra Pradesh & 900 & Operational \\
\hline Ghatgar & Maharashtra & 250 & Operational \\
\hline Punlia & West Bengal & 900 & Operational \\
\hline Poithan (Jayakwadi Dam) & Maharashtra & 12 & Operational \\
\hline Sard ar Sarovar & Gujarat & 1,200 & Patia lly Constructed \\
\hline Tehri & Uttarakhand & 1,000 & Pa tially Constructed \\
\hline Kadana $\mathbf{~} .1$ \& II & Gujarat & 240 & Patially Constructed \\
\hline Nagarjuna Sagar & Telangana & 705 & Patia lly Constructed \\
\hline Total Operational & & 2,612 & \\
\hline Total under Construction & & 3,145 & \\
\hline \multicolumn{2}{|c|}{$\begin{array}{l}\text { Total including under construction } \\
\text { Source: CEA, IEEFA }\end{array}$} & 5,757 & \\
\hline
\end{tabular}

Figure VI. List of Hydropower facilities in India

\section{RECENT DEVELOPMENTS LOOK PROMISING}

India recently amended its 'hybrid wind-solar with storage' policy to clarify that any form of storage - not just batteries could be used in hybrid projects, including PHS, compressed air and flywheels.

In July 2017 the Central Electricity Authority (CEA) released a report focusing on the need to operationalize existing PHS plants built but yet to be commissioned, as well as prospective projects. The CEA estimated there are $96 \mathrm{GW}$ of PHS capacity at 63 sites across India. 
The CEA concluded that a peaking power tariff is required to incentivize PHS in India. Additionally, there is significant capacity that could be added by modernizing and retrofitting existing hydro-electricity capacity with PHS capacity.

Then, in March 2019 India's Ministry of Power proposed electricity rule changes to incentivize electricity supply at times of peak demand, a key pricing signal needed to underpin financial bankability of storage projects. Both government initiatives look very promising.

PHS has traditionally been built in mountainous regions using existing modified upper and lower lakes for reservoirs. IEEFA notes large scale PHS can also be undertaken on a small site using a closed or open water loop, a distinct advantage relative to more complex hydro-electricity dam complexes.

Refurbishing end-of-life dams and adding PHS to existing water storage dams could also inject significant value-add to India's existing portfolio of $45 \mathrm{GW}$ of hydro-electricity capacity.

India has witnessed several PHS proposals:

- In 1970 India's first PHS project commenced at Nagarjuna Sagar in Telangana with an installed capacity of 705 megawatts (MW). The hydroelectricity capacity was commissioned during 1980-85. In 2017 the CEA reported that "the project is not working in pumping mode as the tail pool dam construction took a long time and is still not functional."

- The 1,450 MW Sardar Sarovar dam project in Gujarat has been massively delayed since 1961 due to technical feasibility issues as well as the enormous negative social impact due to submerging 40,000 hectares of land. In September 2017 it was finally reported as having been commissioned as a dam providing flood management, irrigation, drinking water and hydroelectricity capacity, at a financial cost of Rs 16,000 crore (US\$2.3bn). In 2017 the CEA reported that the final component to convert the dam into a $1,200 \mathrm{MW}$ PHS was under construction and due for completion in October 2018, but no confirmation has been reported since.

- In June 2017 Karnataka Power Corporation Limited announced the $2 \mathrm{GW}$ Sharavathy Pumped Storage Project $(8 \times 250 \mathrm{MW})$ in the Shivamogga and Uttara Kannada districts in Karnataka, using the existing Talakalale and Gerusoppa reservoirs. The 2017 construction cost was estimated at a very low Rs 2.5 crores per MW or a total of Rs 4,862 crores (US\$700m) given the limited civil works required, with an estimated construction time of five years.

- In February 2018 the Tamil Nadu Generation and Distribution Corporation (TANGEDCO) confirmed plans for a $500 \mathrm{MW}$ Kundah PHS proposal at a total cost of Rs 1,831 crores (US $\$ 265 \mathrm{~m}$ ) for commissioning in $2022 / 23$. The project finance is being sourced from the Rural Electrification Corporation (REC). Kundah's merits include a low capital cost given it leverages two existing reservoirs: the 'upper' Porthimund and the 'lower' Avalanche-Emerald. Kundah is also in an area least prone to landslides and seismic activity, a key risk in other areas of India.

- In October 2018 Odisha Hydro Power Corp (OHPC) proposed a PHS unit totalling $600 \mathrm{MW}$ at its existing $600 \mathrm{MW}$ hydropower plant at the Indravati multipurpose reservoir in Odisha. The International Finance Corporation (IFC) is planning a \$210 million tender for construction of the project with total investment estimated at Rs 3,000 crore (US\$430m).

- Another 1GW (4 x 250MW turbines) of PHS is proposed on Turga dam in West Bengal. In November 2018 the Japan International Corporation Agency (JICA) announced financing of US $\$ 260 \mathrm{~m}$ for the project, which is not scheduled for completion until 2027.

The emergence of PHS as a key facilitator of variable renewable energy is critical for India. International market developments mirror this thinking.

\section{CONCLUSION}

PHES can address markets that require response times in the region of minutes upwards. The system uses gravel as the storage medium, so it offers a very low-cost storage solution. There are no potential supply constraints on any of the materials used in this system. Plant size is expected to be in the range of 2-5 MW per unit. Grouping of units can provide GW-sized installations. This covers all markets currently addressed by pumped hydro and a number of others that are suitable for local distribution, for example, voltage support. Technology is in development stage and commercial systems are due in 2014.

While hydro-electricity is fraught with social issues in India and many other non-temperate, monsoonal climates and areas of high population densities, PHS has a much smaller footprint.

PHS can play an immensely important role in facilitating India's improved energy security and transition to a lower cost, low carbon electricity market that will require flexible, dispatchable, as well as peak power capacity, especially until battery storage becomes cost competitive. 